\title{
Decontamination of radioactively contaminated sites and advanced methods for their remediation
}

\author{
A. S. Barinov, V. G. Safronov \& S. V. Mikheykin \\ MosSIA "Radon", Moscow, Russian Federation
}

\begin{abstract}
This paper is concerned with the very specific subject of former industrial and municipal wastes dump sites where low level radioactive wastes were buried in the 1940s-1960s in accordance with old radiation protection standards. These dump sites were formerly located in suburban areas but as a result of rapid development of big cities these areas are now to be found in city limits with high populations. Former nuclear research and industrial facilities are also included within these city limits. The problem of safe decontamination, decommissioning and site remediation is an urgent necessity.

Experience of Mos SIA "Radon" has shown that each object is unique and therefore for any project it is necessary to begin searching for all kinds of information that may available. This may be historical records, project designs, construction records and records regarding modifications in the design of the object, radiometric and spectrometry data, and engineering surveys.

For all objects that were commissioned 40-50 years ago, there is no trustworthy information about the design of the buildings and modifications; communications; equipment; contamination and radionuclide composition.

Usually for decontamination of contaminated sites with soil contamination it is necessary to remove contaminated soil and separate fine particles (less than $100 \mathrm{mkm}$ ) which consist of practically $90-95 \%$ contamination
\end{abstract}

Keywords: soil decontamination, radioactive wastes, site characterization, decontamination plan, soil washing process, microgels, erosion protection. 


\section{Introduction}

State Unitarian Enterprise Mos SIA "Radon" are responsible for the radiation safety of the Central region of the Russian Federation with a population $50 \times 10^{6}$. It is a modern facility with the main purpose of treatment and long-term storage of radioactive wastes. Currently, it includes the Center of Technologies of Radioactive Waste Transportation and Emergency Works

Since 1995 the Center has:

- decontaminated 650 historical sites;

- transported 23000 cubic meters of radwastes for treatment and storage;

- dealt with 800 emergency calls;

- decommissioned 10 sites.

At the present time MosSIA "Radon" is well known for having very special experience in development and application in routine decontamination practice, along with new decontamination methods. In the area of their own responsibility Mos SIA "Radon" develops and applies typical decontamination plans, which are very useful for most sites.

The typical decontamination plan includes:

- The characteristic of an object with results of engineering and radiation inspections;

- The concept of normalization of radiation conditions;

- Requirements of works and the order of operations (subdividing of buildings into "contaminated" and "clean" zones, sanitary posts equipment, preparation of necessary communications and equipment, marking of routes for movement and places for temporary storage of radioactive wastes);

- The description of technologies, order, materials, special equipment, tools needed for works;

- Main goals, criteria and limits of decontamination works; planning of manhours; accident plan; waste management strategy;

- The radiating control and maintenance of radiation safety

- Safety requirements, safety assessment

- Detailed plan of control measurements after the end of the decontamination works.

One of the basic and most complicated points of the plan is the choice of optimal techniques and equipment for decontamination. The choice depends on the character of the contamination, levels, scales, the nature and structure of contaminated material, final tasks of decontamination, criteria and limits of decontamination works, design of the building, waste management rules, and the budget.

The decontamination plan, in accordance with the established rules, is necessary in order to submit to customers, the local administration and the regional division of civil defense of the Ministry of Emergency, to take expert advice and to receive the sanitary-epidemiologic conclusion. It is underlined in the conclusion to which sanitary-epidemiologic rules and norms the developed plan corresponds. 


\section{Agricultural research field Volgino, Vladimir region}

The agricultural research field Volgino is located in the Vladimir region of Russia, $150 \mathrm{~km}$ east of Moscow. The All-Union Research Institute of Agricultural radioecology (VNIISHRAE) provided experiments with distribution of radionuclides between soil and different plants from 1972 until 1982. For this purpose a special agricultural field was used:

- Total activity: Sr-90 - $268.8 \mathrm{mCu}$; Cs-137 - $403.2 \mathrm{mCu}$; U-238 - 0.975 $\mathrm{kg}$; Th-232 - $1.950 \mathrm{~kg}$.

- Total area of contamination: $2200 \mathrm{~m}^{2}$

- Penetration of contamination in soil: 0,3 - 0,4 m.

- Estimated volume of contaminated soils $\sim 1500 \mathrm{~m}^{3}$

As result of a full-scale radiological survey by Mos SIA "Radon" it was shown that at this field was located an experimental ladder step contaminated with different radionuclides with different depths of penetration in the soil, three tanks with liquid radioactive wastes (LRW) and two burial sites contaminated with Cs-137 and Sr-90 with an approximate volume of LRW of around $10 \mathrm{~m}^{3}$

Total gamma activity of the contaminated soil (1.0 m under the surface) varied from 60 to $1250 \mathrm{mkR} / \mathrm{h}$.

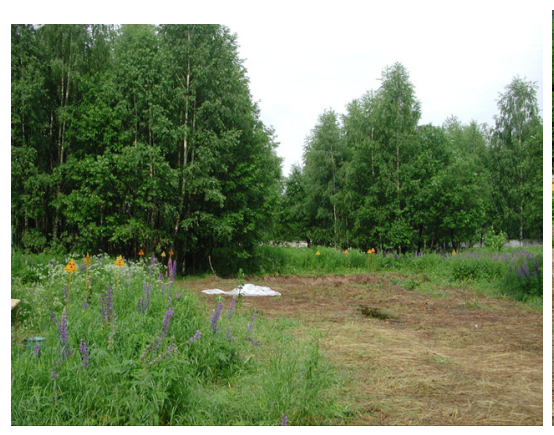

Figure 1: View of experimental field.

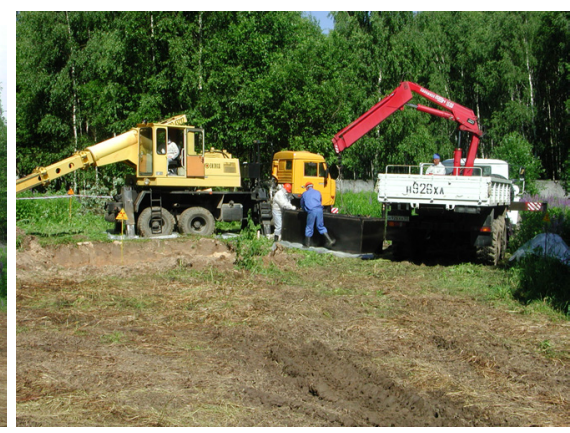

Figure 2: Decontamination and pre-treatment of radioactive wastes.

\section{Waste dumping area near Solnechnoe (Solar) lake (Moscow region)}

The local administration of Ramenskoe village found contamination in June 1985. The contaminated area is about $1.2 \times 10^{-2} \mathrm{~km}^{2}$, located $50 \mathrm{~m}$ to the south of lake Solar, on the territory of a former municipal waste dump site. Full-scale site characterization provided by Mos SIA "Radon" was been carried out in 1994 (foot scale - shooting of territory on a grid 2.0x2.0 m; bore-hole - sampling and analysis; spectrometry of ground and water). Specific activity of Ra-226 is $3 \times 10^{3}$ to $5 \times 10^{5} \mathrm{Bk} / \mathrm{kg}$. The total volume of radioactive wastes is $2600 \mathrm{~m}^{3}$. A 
gamma-survey of the site has shown that contaminations are local and concentrated in a few places with contamination levels at low-intermediate level and radioactive wastes with dose rates from 40 to $2000 \mathrm{mkR} / \mathrm{h}$. The maximum level of dose rate was $3000 \mathrm{mkR} / \mathrm{h}$ at the $0.7 \mathrm{~m}$ depth. Typically contamination is distributed from 0.5 to $4.0 \mathrm{~m}$ deep with the maximum up to $6.0 \mathrm{~m}$. The decontamination plan has been developed and certified.

During the period 2002-2006 MosSIA "Radon" decontaminated, treated and delivered for long-term storage more than $160 \mathrm{~m}^{3}$ of the radioactive wastes. Works are under progress now.

\section{New techniques and equipment currently being developed and tested}

\subsection{Technology of soil washing decontamination}

The vast amount of research after the Chernobyl accident in 1986 has shown that most of the contamination is typically associated with the fine particle fraction of the soil, really it is $90-95 \%$ of total activity in particles with sizes less $0.1 \mathrm{~mm}$. Thus, separation of the fines by various soil washing techniques can be used to effectively decontaminate and reduce the volume of contaminated soil for disposal. Soils contaminated with radionuclides represent a major environmental threat in many parts of the former Soviet Union as the Mayak Production Association (PO Mayak), Kurchatov Institute and numerous other sites worldwide are surrounded by severely contaminated areas including streams, lakes, and soils.

A new soil washing process for soil decontamination was developed by the joint research team the A. A. Bochvar All-Russian Institute of Inorganic Materials (VNIINM) - now successfully moved to Mos SIA "Radon" - and Moscow State University (MSU) to address this environmental challenge. The work was conducted under a U.S. Department of Energy grant from the Initiatives for Proliferation Prevention (DOE IPP) program, managed by Brookhaven National Laboratory. The process gravity segregation of contaminated fine particles, flocculation, uses novel polymeric agents, based on interpolyelectrolytic complexes (IPEC), as recyclable flocculants to costeffectively enhance soil-washing technology.

The pilot-scale soil washing process was based on extensive laboratory-scale research and development. The system engineering design includes: a feeder, a jaw crusher, a washing dram-trammel, an attrition scrubber or ultrasonic equipment, a spiral classifier, a plate thickener, and an oil-water separator. The capacity of the mobile installation is $0.2-1.5 \mathrm{t} / \mathrm{h}$. The decontamination process efficiency is $80-90 \%$ depending on soil type, contamination and the specific process equipment used.

\subsection{Description of the technology and equipment for soil clean-up}

Contaminated soil is pre-treated in the disaggregators. The preliminary treatment is to screen the soil through sieves in order to remove large-sized impurities 
(stones, roots, tree branches) and large soil particles (above $10 \mathrm{~mm}$ ). After the Chernobyl accident it is a well known fact that the bulk of activity is in the fine particles. Table 1 shows the results of laboratory examination of activity distribution by size.

The sieved soil is dispersed in water to form a suspension. Soil particles are classified by gravity into sizes and densities.

Table 1: $\quad$ Results of contaminated soil sieving in water.

\begin{tabular}{|c|c|c|c|c|}
\hline $\begin{array}{c}\text { Size, } \\
\mathrm{mm}\end{array}$ & $\begin{array}{c}\text { Weight, } \\
\mathrm{g}\end{array}$ & $\begin{array}{c}\text { Size } \\
\text { distribution } \\
\%\end{array}$ & $\begin{array}{c}\text { Specific activity } \\
\mathrm{Cs}^{137}, \mathrm{~Bq} / \mathrm{g}\end{array}$ & $\begin{array}{c}\mathrm{Cs}^{137} \text { distribution } \\
\text { by fraction, \% }\end{array}$ \\
\hline Initial soil & 280 & & 42.6 & 1.3 \\
\hline$>2.5$ & 18 & 6.7 & 7.7 & 9.3 \\
\hline $1.0-2.5$ & 12 & 4.5 & 81.2 & 10.1 \\
\hline $0.315-1$ & 148 & 55.0 & 7.1 & 5.0 \\
\hline $0.2-0.315$ & 47 & 17.5 & 11.1 & 4.1 \\
\hline $0.1-0.2$ & 18 & 6.7 & 23.8 & 23.0 \\
\hline$<0.1$ & 26 & 9.6 & 188.8 & 100 \\
\hline Suspension & 8000 & & 0.3 & 42.6 \\
\hline Total & 280 & 100 & &
\end{tabular}

Highly radioactive finely-divided organic and mineral waste particles are concentrated, compacted and disposed of, while the decontaminated soil can be returned to the decontaminated site.

Based on the results of laboratory tests, a technology and a flow sheet were developed for soil decontamination. The pilot installation is currently under construction and it will use a mobile design typical flow sheet of the pilot installation firstly created by the Gormashexport Company for the Kurchatov Institute $[1,2]$.

\subsection{IPEC microgels for remediation of contaminated soils}

Under International Scientific and Technological Center (ISTC, Moscow) Projects \# \#589 and 1567, the Moscow research team in collaboration with JAERI and Los Alamos National Laboratory developed and tested new kinds of interpolyelectrolyte complexes with microgel (\#IPECs) for soil surface stabilization, prevention of radioactive contamination distribution with wind and water streams and for site remediation using mixtures of new water - soluble polymers with seeding grasses [3-10].

Interpolyelectrolyte reactions between loosely cross-linked gels and oppositely charged linear polyelectrolytes were studied. Polyacrylic acid (\#PAA) and poly-N,N-diallyl-N,N- dimethylammonium chloride (\#PDADMAC) were selected. These polyelectrolytic gels are of high swelling capacity $(\sim 1000)$ in pure water but this swelling capacity decreases greatly in the presence of screening low molecular weight electrolytes. 
The kinetics of sorption of linear polyions by oppositely charged polyelectrolytic gels was studied using minor (1-3 g) samples of \#PANa and \#PDADMAC. The conversion of a highly swollen polyelectrolytic gel into the product of the finished sorption (\#IPEC) is schematically shown below.

As soon as a transparent gel sample is immersed into an aqueous oppositely charged linear polyelectrolyte solution it swells greatly. The gel surface develops a very thin dull film that increases in thickness as time passes while the gel sample decreases in volume. In section, this intermediate product shows a macroscopic phase separation into an outer poorly swollen dull \#IPEC shell and the internal core of the initial highly swollen gel. Elemental analysis of these phases evidences that the whole sorbed linear polyelectrolyte is contained only in the outer IPEC shell.

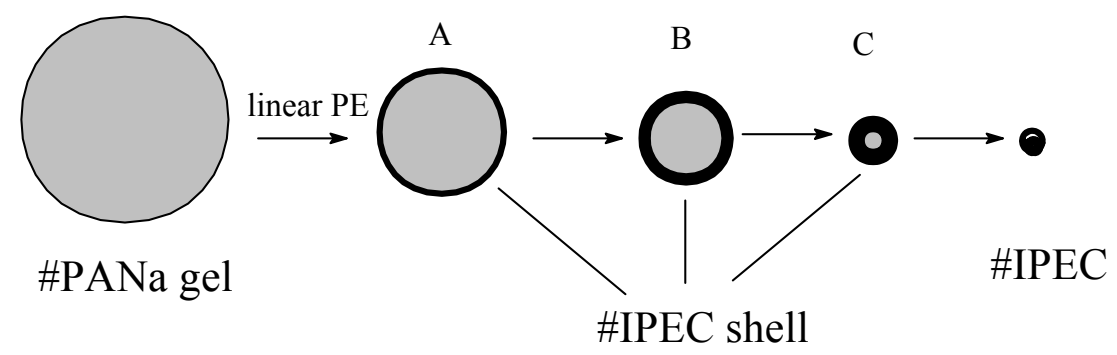

Figure 3: $\quad$ Scheme of \# IPEC formation.

The micro-gel dispersion MGD-2 was injected in combination with MLA-1 in the experiments with water flow - water erosion resistance. With an increase in the water-polymer solution application rate from 2.0 to $4.01 / \mathrm{m} 2$ the soil resistance to eroding water streams changed with a velocity of $55 \mathrm{~cm} / \mathrm{s}(2.0 \mathrm{l} / \mathrm{m} 2)$ and at $70.0 \mathrm{~cm} / \mathrm{s}$ with $4.0 \mathrm{l} / \mathrm{m} 2$. Based on the classification of soils by erosion resistance, soils eroded with a water stream $1 \mathrm{~cm}$ high at a velocity of $50 \mathrm{~cm} / \mathrm{s}$ are considered to be highly erosion-resistant.

It shown that new kinds of IPECs based on micro-gels are very useful as soil stabilizers and applicable as activating agents of grass vegetation in the remediation activities. It may also successfully apply in the post-accidental activities in the case of spray radioactive materials onto top soils.

\section{Effects of IPEC on the water erosion of contaminated soils}

The state of soil aggregation was evaluated in the following way. First, the weighted mean of the soil aggregate diameter was determined following Savvinov's method (dry sieving), and averaged samples weighing $50 \mathrm{~g}$ were prepared. The weighted mean of the diameter of soil aggregates sampled was measured to be $3.27 \mathrm{~mm}$.

In field testing IPEC as MM-1 and microgel dispersion MGD-2, prior to their injection the latter was pre-diluted with water by 10 times and allowed to stay for no less than 12 hours. A 2.0\% MM-1 solution was prepared under field conditions. 
The trenches were made on the south-west slope $\left(3.5^{\circ}\right) 1 \mathrm{~m}$ apart in the form of isosceles triangles ( $25 \mathrm{~cm}$ in base, $25 \mathrm{~cm}$ deep). The trench length to be irrigated was $5.8 \mathrm{~m}$. The IPECs tested were injected by a back-pack sprayer or a watering can. Water streams were supplied with a motor-driven pump from a well-drained pond

The eroding water velocity was $12.0 \mathrm{~cm} / \mathrm{s}$ for the control, $20.0 \mathrm{~cm} / \mathrm{s}$ for the $2.0 \mathrm{l} / \mathrm{m}^{2} \mathrm{MM}-1$ application and $35 \mathrm{~cm} / \mathrm{s}$ for the $4.0 \mathrm{l} / \mathrm{m}^{2} \mathrm{MM}-1$ application, i.e. almost 3 times as high, with a maximum eroding water velocity of $47.0 \mathrm{~cm} / \mathrm{s}$ observed for $2.0 \mathrm{l} / \mathrm{m}^{2}$ MM-1 + 2.0\% MGD-1. With MGD-2, the soil was not denuded by a hydraulic pump (not less $50 \mathrm{~cm} / \mathrm{s}$ ) used during the period under study. This suggests that a combination of $2.0 \mathrm{l} / \mathrm{m}^{2} \mathrm{MM}-1$ and $2.0 \% \mathrm{MGD}-2$ is an optimum polymeric composition for water erosion resistance.

Based on these experiments, the joint application of water soluble polymers and micro-gel dispersions offers great promise.

\subsection{Study of the effect of IPEC on environmental items}

In the greenhouse experiment the first sprouts of the plants under study appeared three days later. The Sudan grass proved to be the least sensitive to soil liquors (containing extra salts introduced from IPEC). The amount that this crop perished was $5-10 \%$ more than that in the control plot. Within seven days of injection of the polymers chemical properties of the IPEC-treated soils were determined. IPEC had little effect on the acidic-basic properties of the soil but changed the electrical conductivity of the liquor extracted from the soil by the standard procedure.

The strength of the coating developed due to treatment of topsoil with formulations based on MM1, MLA1 and micro-gel dispersions MGD-1 and MGD-2 was tested on a laboratory scale. The objective of the present task was to determine the optimum composition of these IPECs and to develop an adequate technique for their introduction.

The results of split and joint application of IPEC components suggest that:

- The coating strength is 1.2-1.5 times as high with split application of IPEC and MG (up to $30.0 \mathrm{~N} / \mathrm{cm}^{2}$ ) as with joint application $\left(20.0 \mathrm{~N} / \mathrm{cm}^{2}\right)$;

- The coating strength is 1.2-1.6 times as high with MGD2 treatment (10.0 $\left.30.0 \mathrm{~N} / \mathrm{cm}^{2}\right)$ as with MGD1 treatment $\left(6.0-20.0 \mathrm{~N} / \mathrm{cm}^{2}\right)$;

- With higher $\varphi$ (MGD/IPEC), the coating strength decreases (from 30.0 $\mathrm{N} / \mathrm{cmm}^{2}$ at $\varphi=0.01$ to $5.0 \mathrm{~N} / \mathrm{cm}^{2}$ at $\varphi=0.2$ );

- The coating strength at $\varphi<0.01$ is higher than that with treatment by IPECs based on MM-1 и MLA-1 alone $\left(6.0-8.0 \mathrm{~N} / \mathrm{cm}^{2}\right)$.

- Micro-gel without IPEC produces a very thin protective layer (1.0-2.0 mm) while a layer only $5-15 \mathrm{~cm}$ thick provides an adequate resistance to water streams.

The technique for introducing these formulations to the soil's interior was optimized on a laboratory scale. The optimization involved introduction of 
micro-gel dispersions, soil loosening and mixing to a given depth at a time. Then the surface was immobilized with IPEC solutions. The strength of the coating produced in such a way was much higher.

\section{Acknowledgements}

Special thanks to Dr. Caroline Mason (Los Alamos National Laboratory), collaborator of ISTC Project \# 1567 for her profound knowledge of the chemistry of actinides and environment and also her unique human qualities. The authors also thank Dr. A. D. Fless (Moscow State University) for his scientific and practical help in researches of soil erosion.

The design and very quick responses to all starting period problems for the soil washing pilot installation were provided by Mr. Stepanenko (Gormashexport Company, Novosibirsk, Russia) personally.

\section{References}

[1] S. V. Mikheikin et al., "Techniques and equipment for closed-cycle decontamination of soils". Waste Management' 05. International Conference, Tucson, USA. 2005

[2] V.G. Volkov, N.N. Ponomarev-Stepnoi, S.G. Semenov, A.D. Shisha, G.G. Gorodetsky, Yu. A. Zverkov, V.V. Kuznetsov, P.P. Poluektov, S.V. Mikheykin, A. Yu. Smirnov "Rehabilitation of radioactively contaminated site of Russian Research Center "Kurchatov Institute": technology development for soil decontamination and recultivation" Waste Management' 04 International Conference, Tucson, USA. 2004

[3] KABANOV, V., et al., Aggregating and Gelling in IPEC solutions, Macromol Chem Symp. 39 (1990) 155-159.

[4] S. V. Mikheikin et al., "The technology of long-term localisation of soils, contaminated with radioactive and high-toxic substances", One decade after Chernobyl: Summing up the Consequences of the Accident (Proc. Int. Conf., Vienna, 1996), IAEA-CN-63/286, IAEA, Vienna (1996). Volume 2. 266-269

[5] S. V. Mikheikin et al., "Interpolyelectrolyte Complexes as Contaminated Topsoil Structureformers", Waste Management'98 (Proc Int. Conf., Tucson, AZ), Tucson (1998) CD-ROM.

[6] S. V. Mikheikin et al., "Polymeric Agents as Toxic Dust and Erosion Suppressants", Dust Aerosols, Loess Soils and Global Change (Proc. International Conf., Washington State University, Seattle), Seattle (1998) 71-74.

[7] S. V. Mikheikin et al., "Modern Techniques For Contaminated Sites Remediation", Waste Management'99 (Proc Internat. Conf., Tucson, AZ), Tucson (1999) CD-ROM.

[8] S. V. Mikheikin et al., "Protection and Recultivation of Soil, Contaminated as a Result of Nuclear Fuel Cycle Activity", Environmental Radioactivity 
in the Arctic (Proc. 4th Internat. Conf., Edinburgh, Scotland) (1999) 232234

[9] S. V. Mikheikin et al., "Interpolyelectrolyte Complexes for Contaminated Soil Immobilization and Remediation", Waste Management'02 (Proc Internat. Conf., Tucson, AZ), Tucson (2000) CD-ROM.

[10] S. V. Mikheykin «Polymeric coats for the stabilization of contaminated surfaces» in IAEA-TECDOC-1403, "The long-term stabilizations of uranium mill tailings". IAEA, Vienna, 2004, pp 265-279 